Supplement of Geosci. Model Dev., 12, 2107-2117, 2019

https://doi.org/10.5194/gmd-12-2107-2019-supplement

(C) Author(s) 2019. This work is distributed under

the Creative Commons Attribution 4.0 License.

(c) (1)

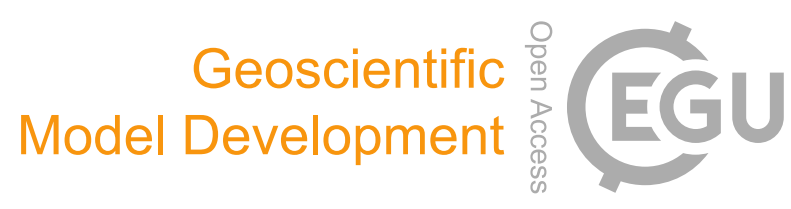

Supplement of

\title{
Convective response to large-scale forcing in the tropical western Pacific simulated by spCAM5 and CanAM4.3
}

Toni Mitovski et al.

Correspondence to: Jason N. S. Cole (jason.cole@ canada.ca)

The copyright of individual parts of the supplement might differ from the CC BY 4.0 License. 
(a)

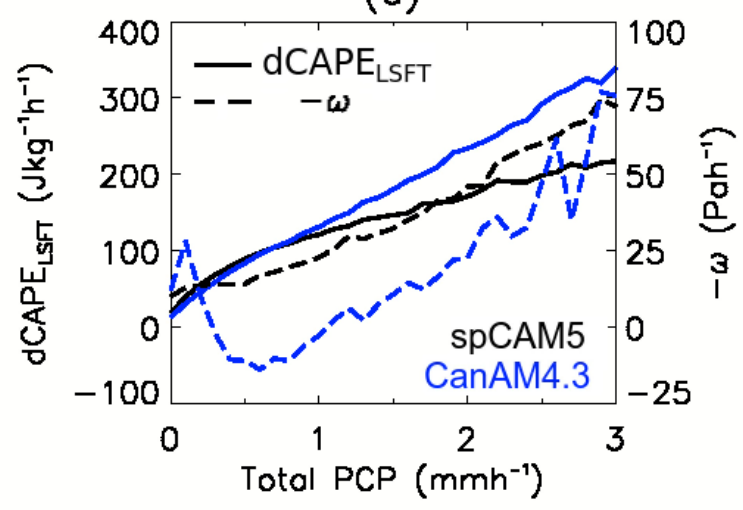

(c)

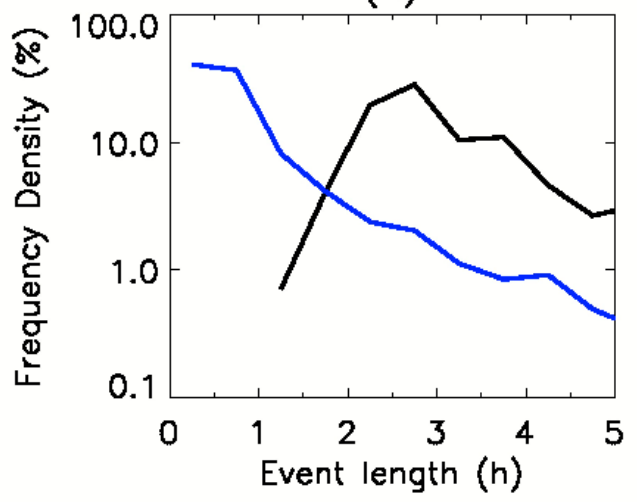

(b)

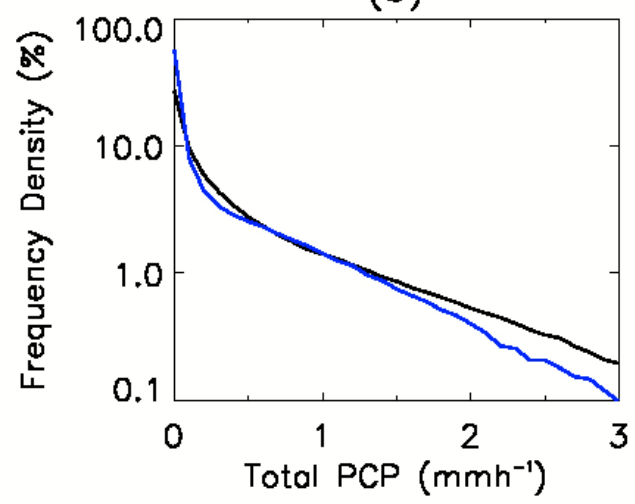

(d)

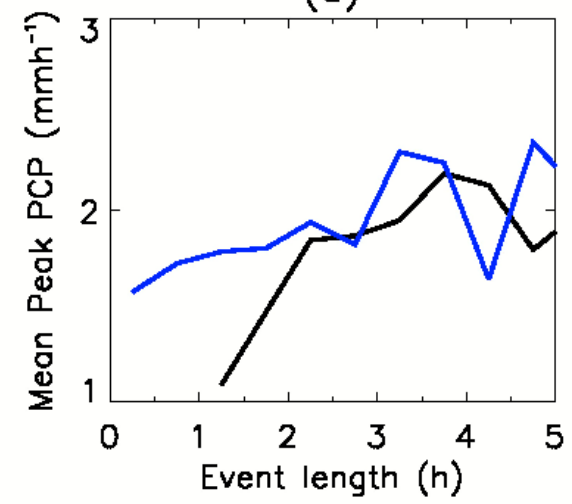

Figure S1: (a) Mean values of CAPE generation in the free troposphere (solid) and near surface large-scale $-\omega$ (dashed) per $0.1 \mathrm{~mm} / \mathrm{h}$ total precipitation bin in spCAM5 (black) and CanAM4.3 (blue), (b) frequency density of total precipitation per $0.1 \mathrm{~mm} / \mathrm{h}$ bin, (c) frequency density of total event length, (d) mean peak total precipitation as function of total event length. 

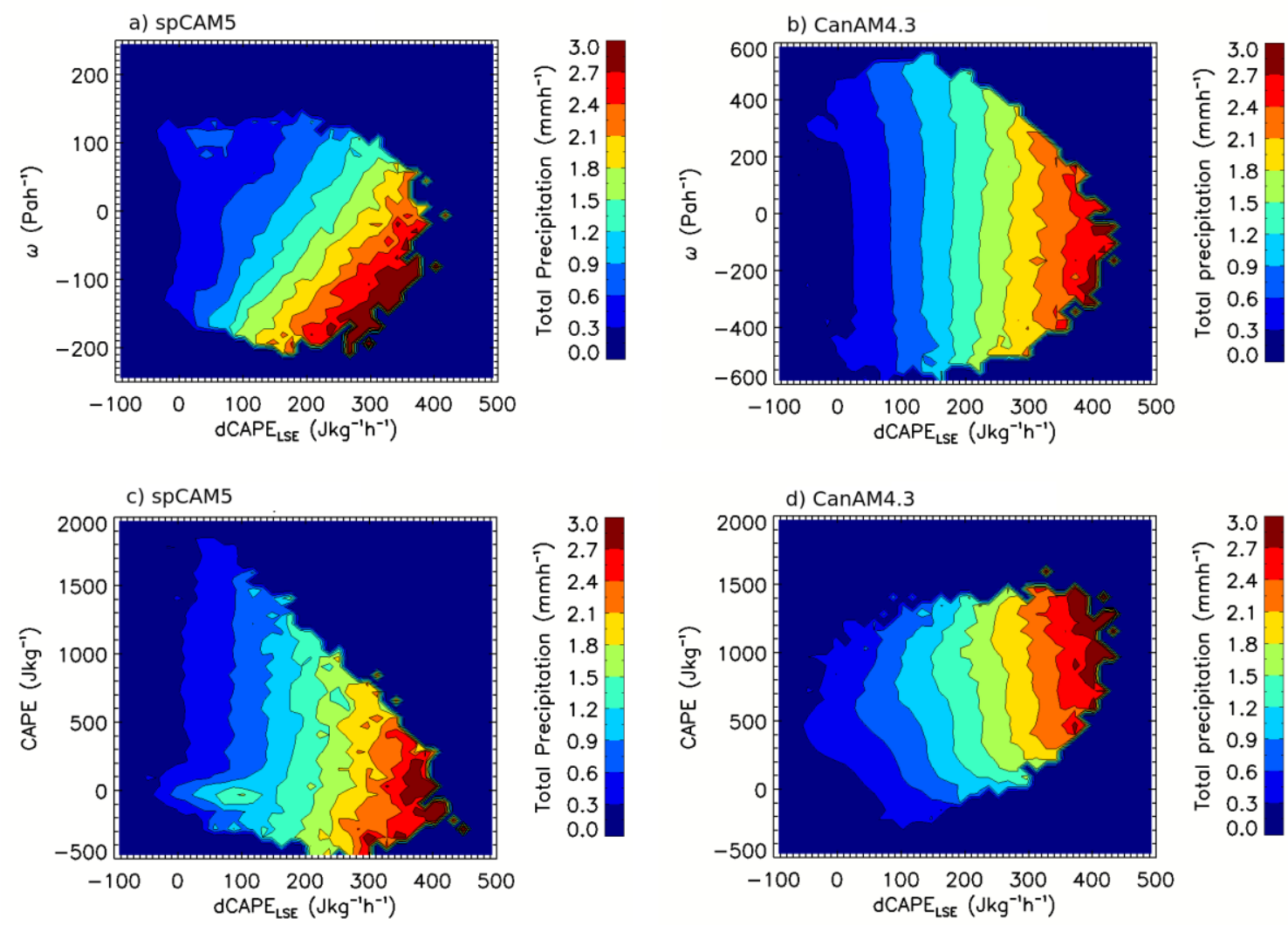

Figure S2: (a) spCAM5 and (b) CanAM4.3 mean total precipitation as function of near surface $\omega$ and dCAPE $_{\text {LSFT. }}$ (c) spCAM5 and (d) CanAM4.3 mean total precipitation as function of CAPE and dCAPE $E_{\text {LSFT. }}$ Each of the plots consists of 1600 bins, 40 on X-axis and 40 on Y-axis. The total precipitation within each bin is an average of at least 20 values. 
a) spCAM5

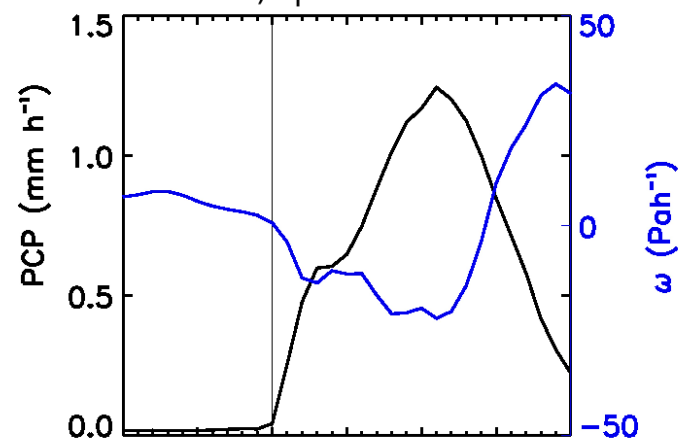

C)

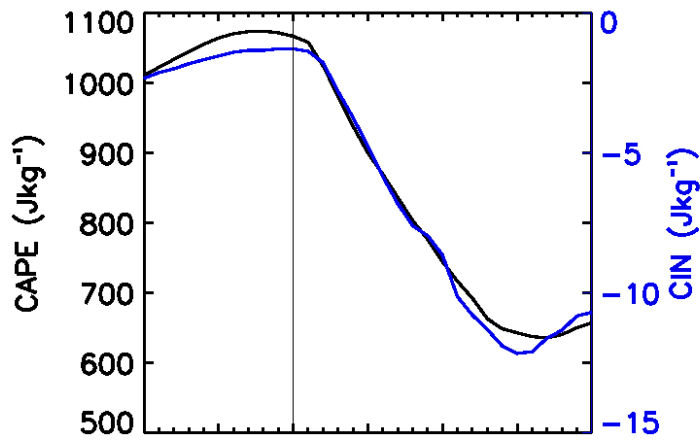

e)

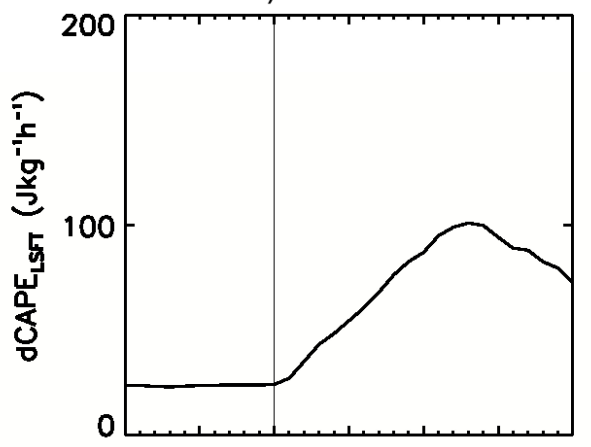

g)

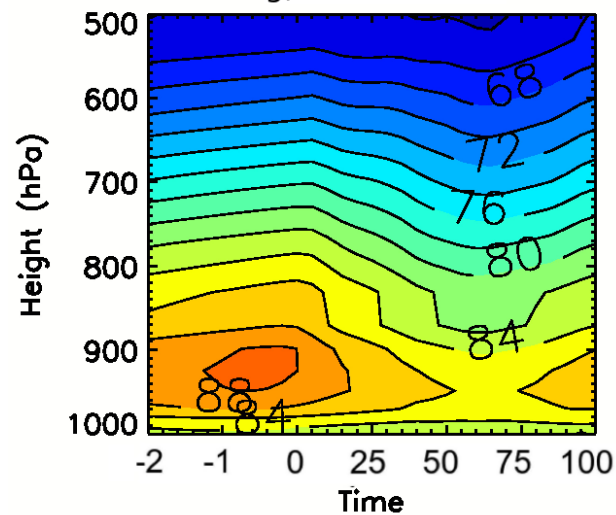

b) CanAM4.3

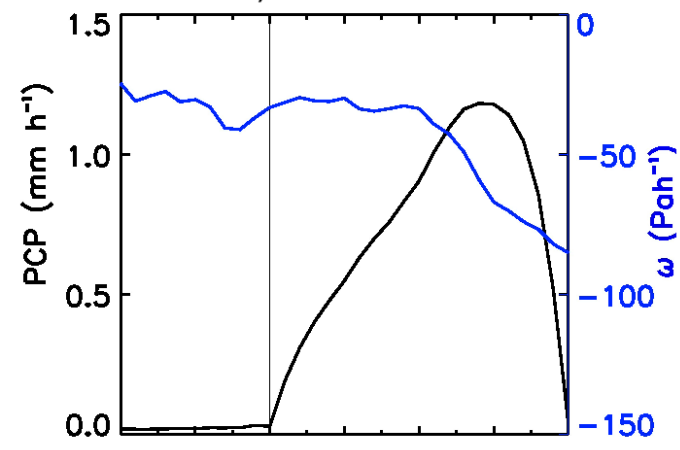

d)

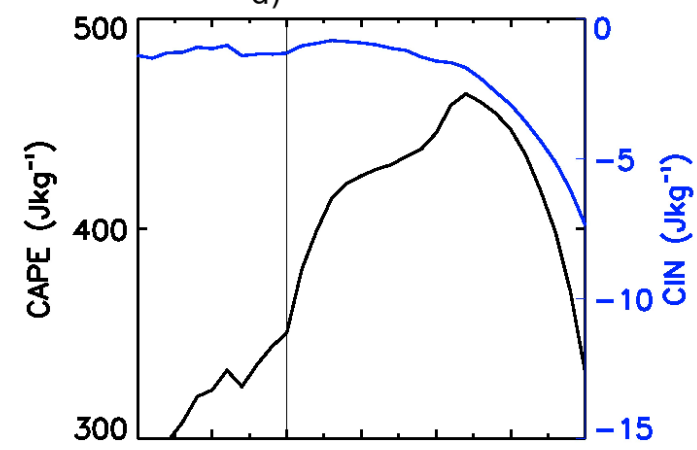

f)

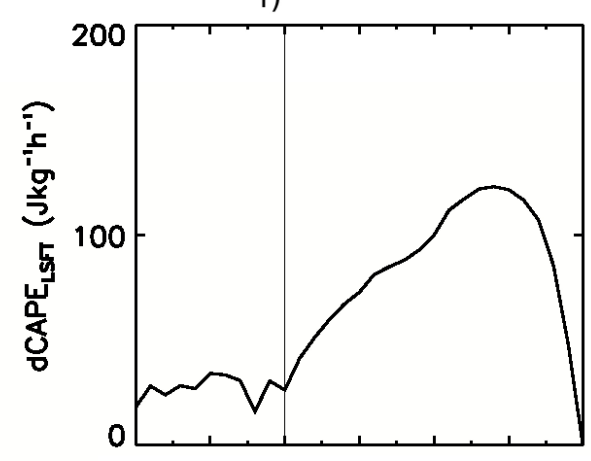

h)

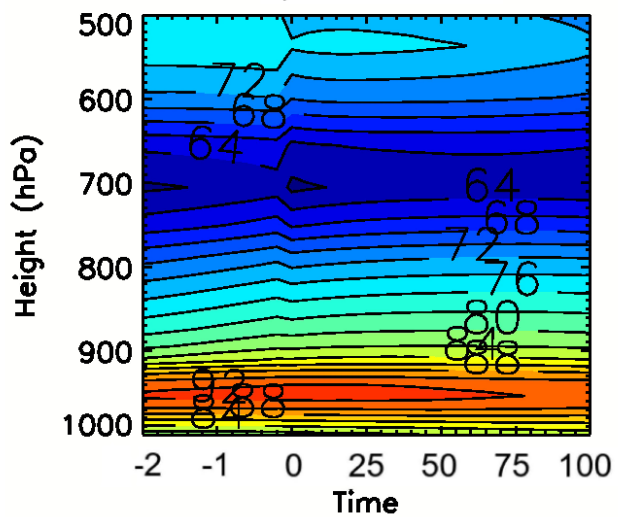

Figure S3: Prior to time $=0$, the time on the $\mathrm{x}$-axis is in hours. After time $=0$, the time is in $\%$ of the event duration time. The rain events start at time $=0$ and end at $t=100$. The $y$-axis on the left shows values for the black curves and the y-axis on the right shows values for the blue curves. The panels on the left are for spCAM5 and the panels on the right are for CanAM4.3. The first row shows total precipitation and largescale near surface $\omega$; the second row shows CAPE and CIN; the third row shows $\mathrm{dCAPE}_{\mathrm{LSFT}}$, and the fourth row show relative humidity patterns. 


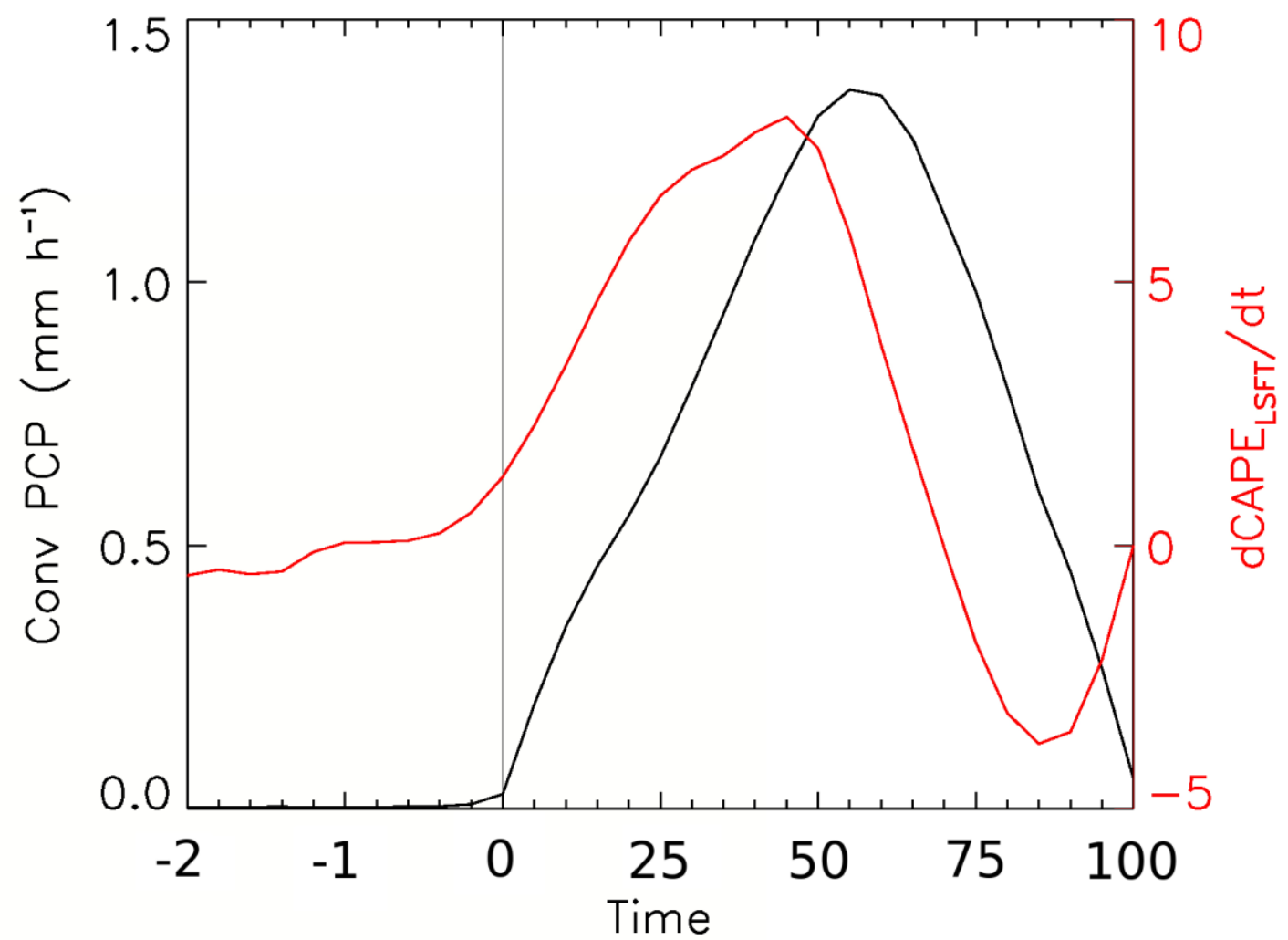

Figure S4: spCAM5 convective precipitation (black) and dCAPE $E_{\text {LSFT }}$ change per 10-minute time interval (red). 